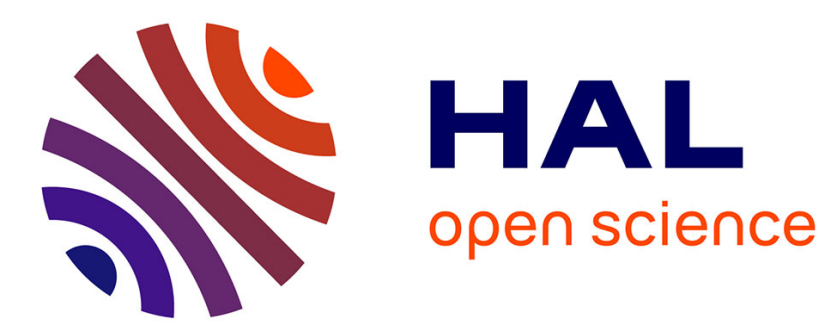

\title{
Capabilities of the dielectric barrier discharge plasma actuator for multi-frequency excitations
}

\author{
N Benard, E Moreau
}

\section{To cite this version:}

$\mathrm{N}$ Benard, E Moreau. Capabilities of the dielectric barrier discharge plasma actuator for multifrequency excitations. Journal of Physics D: Applied Physics, 2010, 43 (14), pp.145201. 10.1088/0022$3727 / 43 / 14 / 145201$. hal-00597818

\section{HAL Id: hal-00597818 https://hal.science/hal-00597818}

Submitted on 2 Jun 2011

HAL is a multi-disciplinary open access archive for the deposit and dissemination of scientific research documents, whether they are published or not. The documents may come from teaching and research institutions in France or abroad, or from public or private research centers.
L'archive ouverte pluridisciplinaire HAL, est destinée au dépôt et à la diffusion de documents scientifiques de niveau recherche, publiés ou non, émanant des établissements d'enseignement et de recherche français ou étrangers, des laboratoires publics ou privés. 


\title{
Capabilities of Dielectric Barrier Discharge Plasma Actuator for Multi-Frequency Excitations
}

\author{
N. Benard ${ }^{1}$ and E. Moreau ${ }^{1}$
}

\section{Abstract:}

The natural instability mechanisms are inherent in most of the laminar and turbulent flow configurations. Usually, these instabilities result in the formation of flow structures occurring at diverse spatial and time scales. An effective control requires an actuator able to bring momentum transfer over a wide range of frequency to act on these instabilities. Promising results are expected for such control strategy because, according to stability theory, a small amplitude perturbation can be large enough to produce significant effects even at high Reynolds number. Moreover, simultaneous production of small perturbations at several frequencies can enhance or cancel non linear interactions; this opens alternative methods for flow control. The focus of the present study is to demonstrate the ability of plasma actuators to introduce flow perturbations at single and dual frequencies by simply adjusting the waveform of the voltage applied to the plasma actuator. The flows produced by a dielectric barrier discharge supplied by burst, superposition and ring modulations are described in temporal and frequential domains. The results confirm the potential of non-thermal plasma actuators to produce highly unsteady flows at single, double or multiple frequencies.

\section{Introduction}

For a few years, active airflow control by plasma actuator has been enriched by a comprehensive literature. Practically, a surface plasma actuator operates by applying a high voltage between at least two electrodes placed on both sides or on the top of a dielectric material. The electric field results in a weakly ionized region above the dielectric. The electrochemical interactions between air and plasma lead to complex plasma kinetic phenomena due to coexistence of low density of electrons, positive and negative ions and neutral particles [1-2]. Such plasma discharges produce a wall tangential jet flow [36] due to a self-sustaining process involving high rate of collisions between neutral and charged particle [7-8].

Substantial efforts have been done to increase the electric wind velocity by modifying the geometry of the actuator [5, 9] or by adjusting the electrical signal [10]. However, the time-averaged produced electric wind does not exceed $7 \mathrm{~m} / \mathrm{s}$ in the case of a single dielectric barrier discharge (DBD). Basically, this confines the use of plasma actuators to flow regimes corresponding to moderate

\footnotetext{
${ }^{1}$ Laboratoire d'Etudes Aérodynamiques (LEA), Université de Poitiers, ENSMA, CNRS Bld Marie et Pierre Curie, Téléport 2, 86962 Futuroscope Cedex, France
} 
external velocity (typically lower than $50 \mathrm{~m} / \mathrm{s}$ ) [11-12]. In most cases, control of flow at Reynolds number higher than 500000 remains a real challenge.

Most of the practical flows are turbulent, which involves simultaneous occurrence of multiscale flow structures. Both in laminar and highly turbulent flows, there exists strong linear interactions between the coherent structures which dominate the global dynamics of flow. However, threedimensional effects can not be neglected in turbulent regimes. These effects are related to non-linear processes mostly occurring at high frequency (small scale interactions). As widely explored in the literature material [13-14], one can take significant advantage of the multi-scale aspect of turbulent regimes. Regardless of the control technology, significant improvements in the control performance have been reported when excitation frequency matches the natural frequency related to the large-scale flow structures [15]. Excitations at high frequency can also affect turbulent flows by a mechanism still debated in the community [16-17]. To improve the control effects by amplification or cancellation of the linear and non-linear interactions, one can generate perturbations at one, two or multiple frequencies, simultaneously.

Usually, active control systems are based on mechanical construction. Therefore, such actuators are not fast enough to reach the bandwidth required for multi-frequency actuation. This point is especially verified in laboratory experiments as, in laboratory conditions, the model sizes are much lower than real ones whereas the frequencies are higher. The high bandwidth operability of plasma actuator is established [18], suggesting a high potential for multi-frequency forcing. Usually, flow control by surface plasma is designed to act on a mono-frequency target. For instance, TollmienSchlichting instabilities of a boundary layer can be suppressed or amplified through non-linear processes promoted by a plasma forcing [19]. Another example is the use of non-thermal plasma discharge to excite instability modes of axisymmetric jet flow [20]. Effective flow separation control by plasma seems also involved action on the instability mechanisms originating at the separation point [11-12, 21-22]. In most of the studies related to unsteady actuation by plasma discharge, the local jet flow resulting from such operating conditions is not detailed. A better knowledge of the electric wind produced by a DBD operating under modulation can be helpful to increase the effectiveness of plasma actuator to control turbulent flows. Furthermore, new control strategies relative to non-linear reinforcement or stabilization of the flow structures may emerge from the capability of plasma discharge to produce airflow composed of multi-frequency components.

The present study proposes to investigate how the surrounding fluid, initially stagnant, reacts to a plasma surface discharge driven by modulated electrical signals. The produced airflow resulting from simple sine waveform is briefly presented as the reference case. Then, burst modulations, signal superposition and ring modulations are successively introduced and discussed. The correlation between the applied voltage and the resulting produced airflow in temporal and frequential domains are presented. Measurements are performed by a Laser Doppler Velocimetry (LDV) system permitting 
the time-history description of the induced airflow. The main objective is to highlight the opportunity of multi-frequency excitations using a conventional single DBD non-thermal plasma actuator.

\section{Method}

The typical single DBD actuator used in the present study consists of two thin electrodes flush mounted on both sides of a 3-mm-thick dielectric plate (PMMA, $200 \times 200 \mathrm{~mm}^{2}$ ). The width of airexposed electrode (active electrode) is $10 \mathrm{~mm}$ whereas the grounded electrode is wider $(20 \mathrm{~mm})$ that allows a full plasma extension (figure 1). The inter-electrode space is $5 \mathrm{~mm}$. The grounded electrode is embedded in epoxy resin to avoid the discharge below the plate.

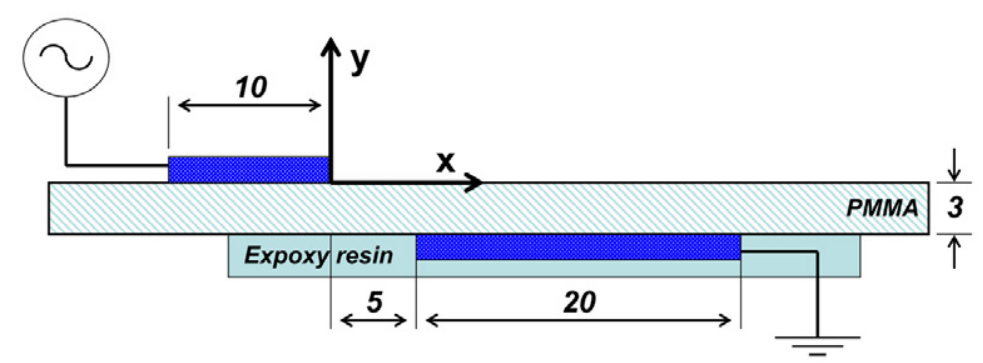

Figure 1: Sketch of the single DBD actuator

Ignition of a weakly ionized region requires an onset voltage high enough in amplitude to exceed the breakdown voltage of air. Here, the voltage varies as a sinusoidal waveform at amplitude of $18 \mathrm{kV}$ and frequency $\mathrm{f}_{\mathrm{AC}}$ (this frequency can be changed according to the studied case but most of the experiments are performed at $\mathrm{f}_{\mathrm{AC}}=1500 \mathrm{~Hz}$ ). This sinusoidal waveform composes the carried signal necessary to initiate and sustain the plasma and its expected to contain mono-frequential component $[5,23]$. Different low voltage signal modulations are also generated:

- The first corresponds to a burst modulation. It consists of switching on and off the discharge at a frequency $\mathrm{f}_{\mathrm{BM}}$ (figure 2a). Such modulation is performed by multiplication of the carried sinusoidal signal (at $\mathrm{f}_{\mathrm{AC}}$ ) by a pulse square wave having an adjustable frequency $\mathrm{f}_{\mathrm{BM}}$ and duty-cycle fixed at $50 \%$ (here the effects of duty-cycle are not investigated but results can be find in [24]). The burst modulation should result in dual-frequency characteristic in spectral domain (frequency peaks at $\mathrm{f}_{\mathrm{AC}}$ and $\left.\mathrm{f}_{\mathrm{BM}}\right)$.

- The second modulation concerns a superposition mode (figure $2 \mathrm{~b}$ ). The carried signal is added to a second sinusoidal waveform having a frequency $f_{S M}$. The frequency $f_{S M}$ has to be one order of magnitude lower than $\mathrm{f}_{\mathrm{AC}}$. According to signal processing theory, such modulation produces two sidebands at $\mathrm{f}_{\mathrm{SM}}$ and $\mathrm{f}_{\mathrm{AC}}$. 
- The third modulation is about typical ring modulation simply based on multiplication of two sinusoidal waveforms (figure 2c). The amplitude of the carried sine signal at $f_{A C}=1500 \mathrm{~Hz}$ is periodically varied by a carrying, or modulating, signal having a lower frequency $f_{R M}\left(f_{R M}\right.$ can vary). Ring modulation is very similar to typical amplitude modulation. The two main differences are a) ring modulation is ever varied by $100 \%$ above and below its unmodulated level, and b) ring modulation is composed of two sidebands in frequency domain (at $f_{A C}-f_{R M}$ and $f_{A C}+f_{R M}$ ) when the DC offset of amplitude modulation means that the carrier frequency remains in the output signal. As a result, ring modulation has theoretically no fundamental at $f_{\mathrm{RM}}$.

These generated low voltage signals are send to the memory bank of a signal generator (Hameg HM8131). The voltage amplitude at the generator output is fixed at $6 \mathrm{~V}$. Then, a signal amplifier (Trek, model $30 / 40 \mathrm{~mA}$ ) is used to apply a gain of $3000 \times$ to the input voltage. This results in modulated signals having amplitude of $18 \mathrm{kV}$. Measurements of the electrical power consumptions are given in table 1.

a)

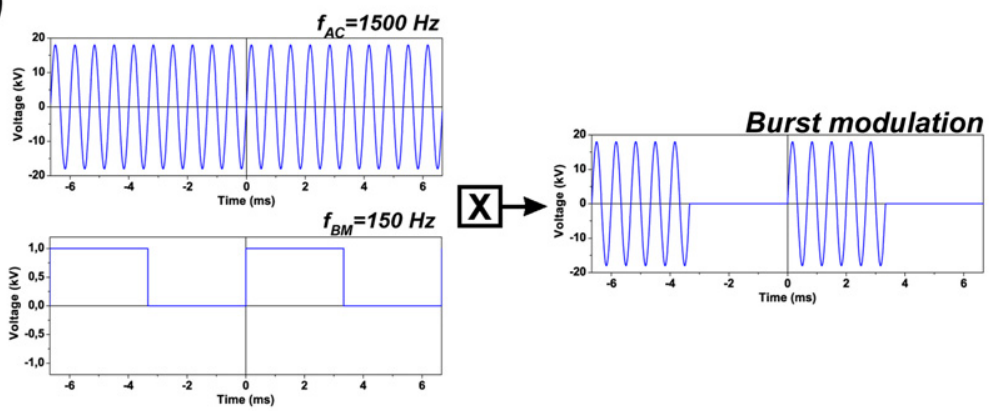

b)

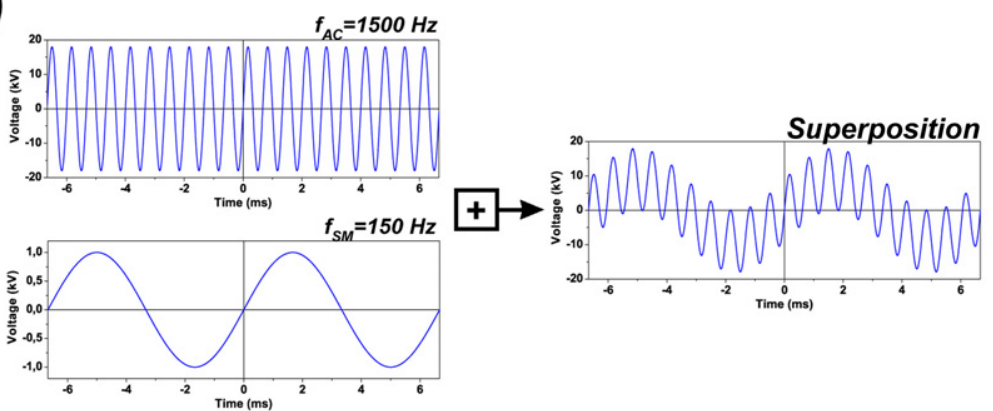

c)
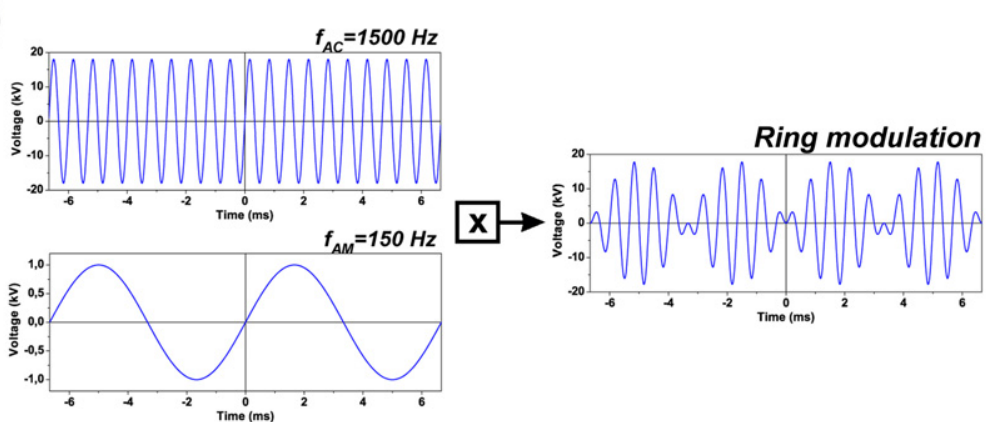

Figure 2: illustrations of the burst, superposition and ring modulations 
Sine waveform (no modulation)

\begin{tabular}{lll}
\hline$f_{A C}$ & $150 \mathrm{~Hz}$ & $0.086 \mathrm{~W} / \mathrm{cm}$ \\
$f_{A C}$ & $1000 \mathrm{~Hz}$ & $0.522 \mathrm{~W} / \mathrm{cm}$ \\
$f_{A C}$ & $1500 \mathrm{~Hz}$ & $0.750 \mathrm{~W} / \mathrm{cm}$ \\
& & \\
\multicolumn{3}{l}{ Burst modulation $\left(f_{A C} 1500 \mathrm{~Hz}, D C=50 \%\right)$} \\
\hline$f_{B M}$ & $50 \mathrm{~Hz}$ & $0.365 \mathrm{~W} / \mathrm{cm}$ \\
$f_{B M}$ & $150 \mathrm{~Hz}$ & $0.362 \mathrm{~W} / \mathrm{cm}$ \\
$f_{B M}$ & $300 \mathrm{~Hz}$ & $0.325 \mathrm{~W} / \mathrm{cm}$
\end{tabular}

Superposition modulation $\left(f_{A C} 1500 \mathrm{~Hz}\right)$

\begin{tabular}{|c|c|c|}
\hline $\begin{array}{l}f_{S M} \\
f_{S M} \\
f_{S M}\end{array}$ & $\begin{array}{l}50 \mathrm{~Hz} \\
150 \mathrm{~Hz} \\
300 \mathrm{~Hz}\end{array}$ & $\begin{array}{l}0.118 \mathrm{~W} / \mathrm{cm} \\
0.155 \mathrm{~W} / \mathrm{cm} \\
0.201 \mathrm{~W} / \mathrm{cm}\end{array}$ \\
\hline \multicolumn{3}{|c|}{ Ring modulation $\left(f_{A C} 1500 \mathrm{~Hz}\right)$} \\
\hline $\begin{array}{l}f_{R M} \\
f_{R M} \\
f_{R M}\end{array}$ & $\begin{array}{l}50 \mathrm{~Hz} \\
150 \mathrm{~Hz} \\
300 \mathrm{~Hz}\end{array}$ & $\begin{array}{l}0.315 \mathrm{~W} / \mathrm{cm} \\
0.327 \mathrm{~W} / \mathrm{cm} \\
0.305 \mathrm{~W} / \mathrm{cm}\end{array}$ \\
\hline
\end{tabular}

Table 1: Typical electrical power consumption according to the applied waveform with $\mathrm{V}=18 \mathrm{kV}$.

At quiescent flow conditions, the actuation produced a local airflow above the dielectric wall. Time-resolved velocities and power spectra densities are measured using a mono-component Laser Doppler Velocimeter (LDV). The light source is a $5 \mathrm{~W}$ Argon-ion laser. Two intersecting green beams (wavelengths of $488 \mathrm{~nm}$ ) compose the measurement volume (the probe surface is $0.2 \times 1 \mathrm{~mm}^{2}$ ). Then, the near-wall measurements are limited to a minimum distance of $0.1 \mathrm{~mm}$ from the dielectric surface (i.e., in the y-direction) and velocity is spatially averaged over $0.2 \mathrm{~mm}^{2}$. The optical system is fixed on a micrometric displacement system $( \pm 0.01 \mathrm{~mm})$. The optic arrangement is set to measure the primary velocity component of the produced wall jet flow (U-component in the x-direction). The LDV system measures the velocity of dielectric oil droplets (Ondina 15, Shell) which seed the enclosed flow. The mean size of these droplets is of about $0.5 \mu \mathrm{m}$. The small size of these particles insures that they accurately follow the overall flow field while the charged effects can be neglected [25]. To ease the seeding, the actuator is placed in an airtight glass box whose dimensions are sufficient to limit the wall effects on velocity measurements $\left(300 \times 400 \times 800 \mathrm{~mm}^{3}\right)$. The sampling frequency varies in 14-24 $\mathrm{kHz}$ range and 800,000 bursts are stored for each acquisition points. A slotting method including a weight scheme is coded to post-process the stochastic signal issuing from the LDV system [26]. Finally, the power spectra densities are computed for the fluctuating parts of the induced airflows. For the time evolution of the velocity, the acquisition rate is sometime too low to accurately describe the flow dynamic (only 9 to 16 data points per cycle). In these cases, a phase reconstruction algorithm is applied. This algorithm considers 45,000 modulated cycles. The 45,000 periods are superimposed by an adequate time shift. Then, the resulting oversampled period is discretized in 400 bins. Finally, a weighted ensemble average is performed for each bin. This average considers approximately 1000 data points at least and results in a final temporal resolution of $1.66 \mu \mathrm{s}$.

The waveforms applied to the actuator, the velocity acquisitions and the voltage measurements are realized by using an external computer with a customized LabVIEW interface which allows synchronous measurements (figure 3). 


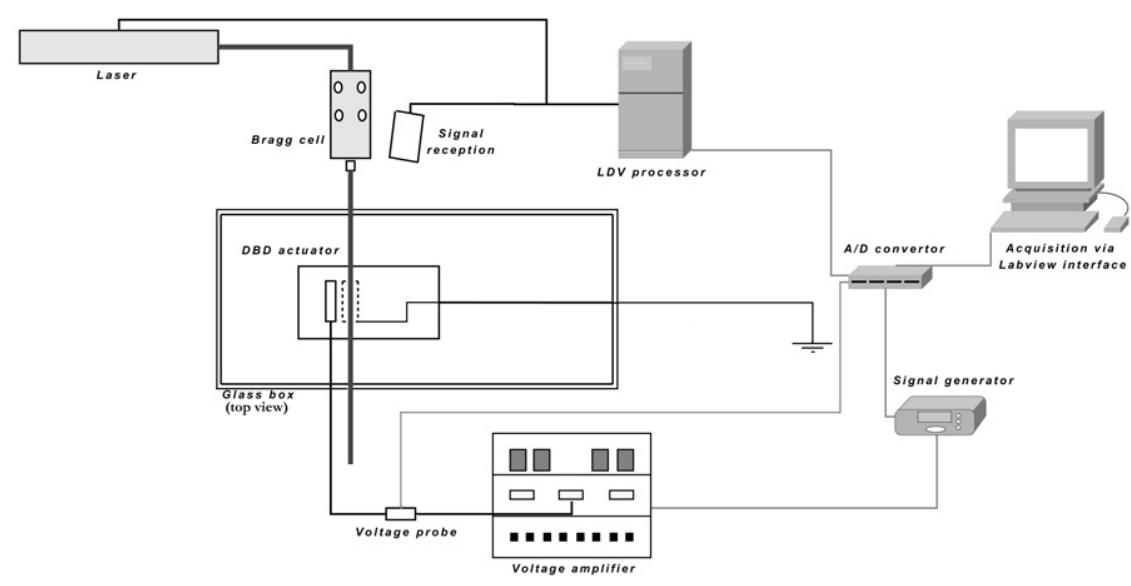

Figure 3: Principle of the acquisition system and the experimental setup

\section{Results}

\subsection{Simple frequency excitation: Sine input signal}

First, a sine signal is applied to the active electrode. Such input signal is widely used in literature to control airflow and/or give better insights on the force production process. The upper limit of the driven frequency is numerically of about $100 \mathrm{kHz}$ [27], but transmission of the excitation frequency to the surrounding airflow has been verified from $500 \mathrm{~Hz}$ up to $1500 \mathrm{~Hz}$ [5, 23-24]. This basic input signal is briefly described here. Sine waves having frequency, $\mathrm{f}_{\mathrm{AC}}$, from 150 up to $1500 \mathrm{~Hz}$ are applied to the active electrode of the single DBD actuator while time-resolved measurements of the electric wind are performed.

Theoretically, a sinusoidal waveform presents a pure signal characteristic with a monofrequency component. The high-voltage waveform at the air-exposed electrode is measured and the related Power Spectra Density (PSD) are calculated by a FFT algorithm (Hanning windowing, n$\mathrm{fft}=2048$, averaged over $100 \mathrm{AC}$ cycles). The frequency content of the applied voltage is dominated by fundamental $\mathrm{f}_{\mathrm{AC}}$ (Figure 4). Low amplitude harmonics can occur due to small deformation at the change in the voltage sign inherent to the specification of the amplifier (slew-rate of $350 \mathrm{~V} / \mu \mathrm{s}$ ). It is assumed that these harmonics are vanished in the transduction process promoted by the plasma discharge. 

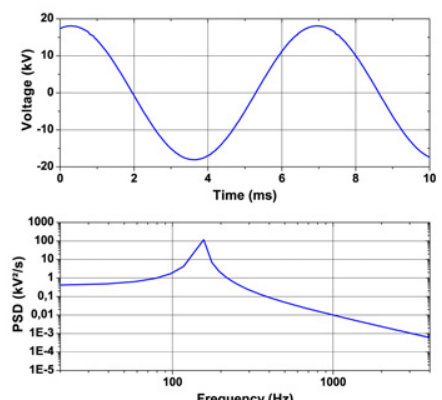

(a)
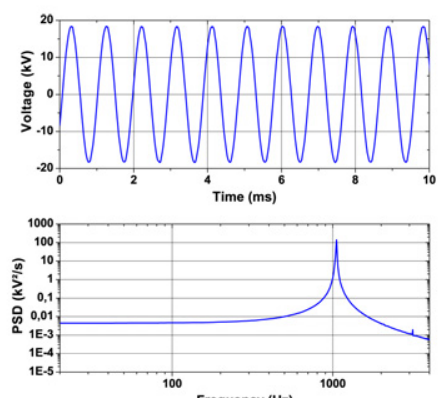

(d)
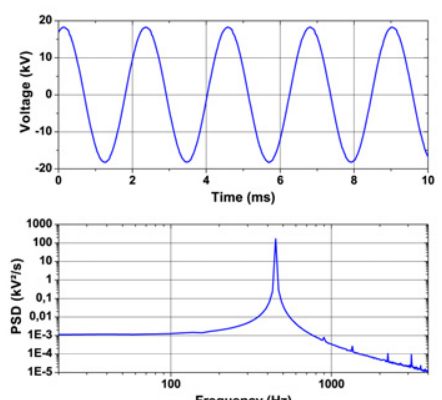

(b)
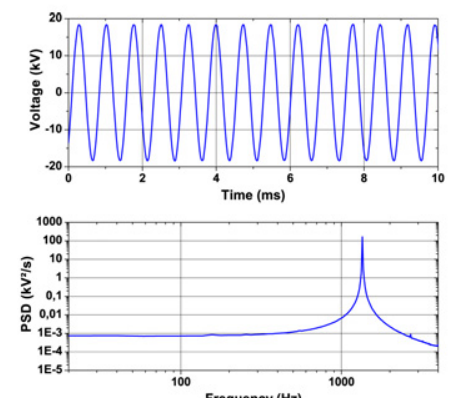

(e)
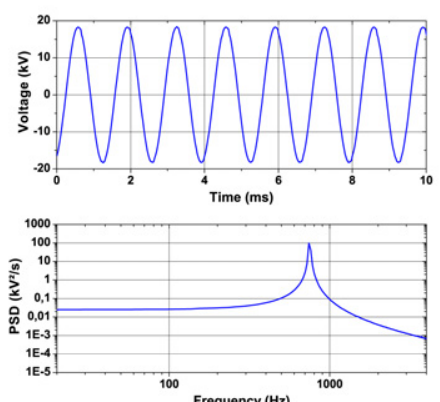

(c)
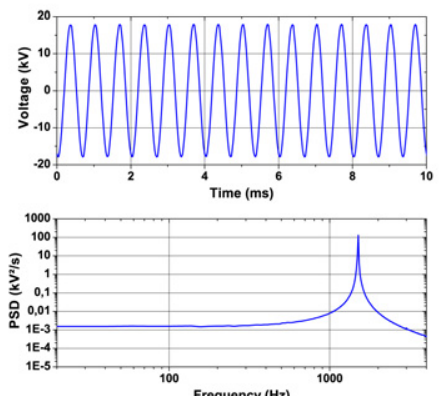

(f)

Figure 4: Measured signals at the DBD and corresponding spectra densities for $\mathrm{f}_{\mathrm{AC}}$ equal to (a) $150 \mathrm{~Hz}$, (b) 450 $\mathrm{Hz}$, (c) $750 \mathrm{~Hz}$, (d) $1050 \mathrm{~Hz}$, (e) $1350 \mathrm{~Hz}$ and (f) $1500 \mathrm{~Hz}$.

A sample of the electric wind time-history is plotted in figure 5a for a DBD supplied by a sine wave at $\mathrm{f}_{\mathrm{AC}}=150 \mathrm{~Hz}$ (at $\mathrm{x}=3 \mathrm{~mm}$ and $\mathrm{y}=1 \mathrm{~mm}$, see figure 1 for the coordinate system). The velocity signal presents a pattern repeating at $150 \mathrm{~Hz}$ but the velocity production is not uniform over the whole period of a sine wave. Indeed, as previously reported in [5], the negative-going-cycle (glow regime) relates to velocity production when the positive-going-cycle (streamer regime) leads to a velocity decrease. Here, at low $\mathrm{f}_{\mathrm{AC}}$, the velocity signal behaves as a train of pulses. At high $\mathrm{f}_{\mathrm{AC}}$, a phase reconstruction is required to accurately access the time-resolved velocity generated by the plasma. Figure $5 b$ presents the electric wind dynamic estimated by phase reconstruction when the DBD is operated at $\mathrm{f}_{\mathrm{AC}}=1500 \mathrm{~Hz}$. In this case, the electric wind oscillates according to a nearly sine wave at $\mathrm{f}_{\mathrm{AC}}=1500 \mathrm{~Hz}$. Again, only half the signal period produces an increase in velocity. One can notice that the location of the measurement is not optimized to access the maximal induced airflow that explains the low produced electric wind in regard to previous published results.

These time-resolved results highlight the improvement of the mean produced electric wind observed for increasing $\mathrm{f}_{\mathrm{AC}}[5,10,28]$. At low $\mathrm{f}_{\mathrm{AC}}$, it has been verified that the signal period related to lower velocity production (i.e., streamer regime) is longer than at high $\mathrm{f}_{\mathrm{AC}}$ (data not shown). As a result, the mean produced velocity is lower at low $\mathrm{f}_{\mathrm{AC}}$ whereas the amplitude of the relative velocity fluctuation, $\mathrm{u}^{\prime} / \mathrm{u}_{\max }$, is enhanced (verified for $150<\mathrm{f}_{\mathrm{AC}}<1500 \mathrm{~Hz}$ at $\mathrm{x}=3 \mathrm{~mm}$ ). 


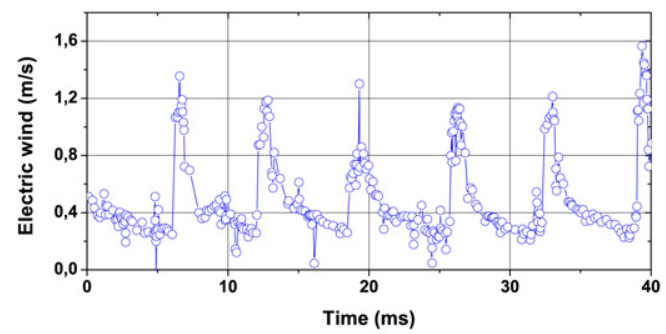

(a)

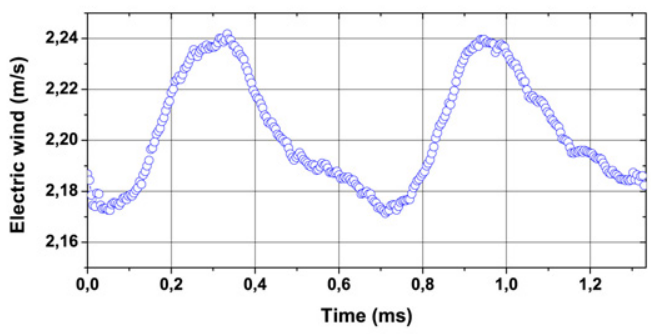

(b)

Figure 5: Time-history of the induced airflow when excited by a sine wave at (a) $f_{A C}=150 \mathrm{~Hz}$ and (b) $f_{A C}=1500$ $\mathrm{Hz}$ (phased reconstruction).

The frequency domain description downstream of the plasma is performed by analysing the power density spectra at different $x$ locations $(x=5,10$ and $15 \mathrm{~mm}$, at $y=1 \mathrm{~mm}$ when a visible plasma extension of about $2-5 \mathrm{~mm}$ is expected). This is conducted to quantify amplification or attenuation of the spectral component further downstream the plasma region. Results for fundamental frequencies at 300,900 and $1500 \mathrm{~Hz}$ are plotted in figure 6. As observed in figure 5, the induced airflow behaves as a pulsed train at low $\mathrm{f}_{\mathrm{AC}}$ and looks like a sine waveform at high $\mathrm{f}_{\mathrm{AC}}$. As a result, the produced airflow has a fundamental at $f_{A C}$ but significant harmonics are produced every $n f_{A C}$. At the lowest $f_{A C}$, the total energy content in the fluctuating part of the produced flow (i.e., the integral of PSD over the frequency range considered) decrease with $x$ location (Fig. 6a). Sine signal at higher $\mathrm{f}_{\mathrm{AC}}$ distinguish by amplification of the total energy, and more specifically, of the fundamental peak amplitude, this up to $10 \mathrm{~mm}$. This should relate to a longer plasma extension at higher frequency that enlarges the region of momentum transfer by a suspected cumulative effect of energy exchanges between charged and neutral particles (additional data indicate that amplitude of fluctuations linearly increases with the plasma extension). Conversely, a lower frequency $\mathrm{f}_{\mathrm{AC}}$ produces an expansion of plasma reduced, which explains a faster dissipation of energy beyond the end of plasma extension due to viscous effects. More specific comments on energy transfer over frequency bands (and then over the different fluctuation scales) can be made. In addition to the fundamental peak, the 'high-frequency' excitation leads to increased energy distributed over a broadband spectrum (but still centered on the fundamental, see figure $6 \mathrm{c}$ at $5 \mathrm{~mm}$ for instance). For location further downstream the plasma sheath, new distribution of energies over frequency occurs. It seems that energies of high frequency content are transmitted to the lower frequency ranges. 

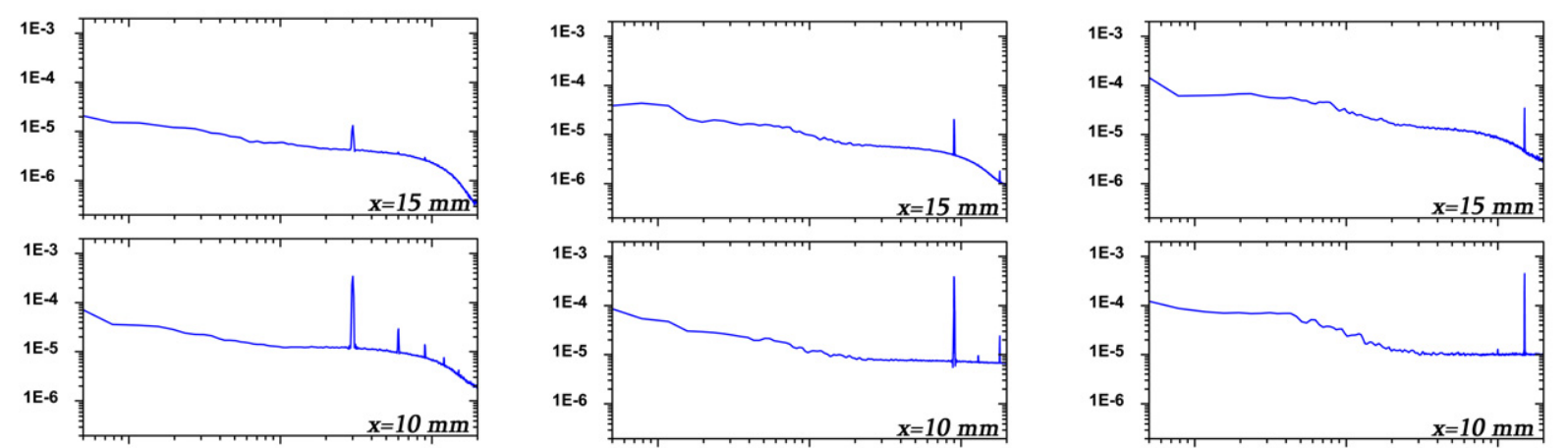

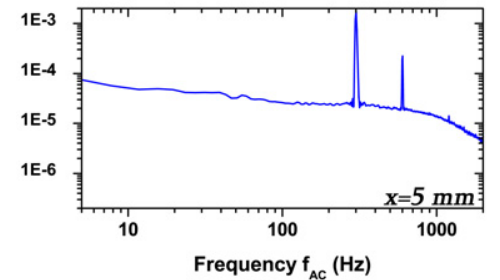

(a)
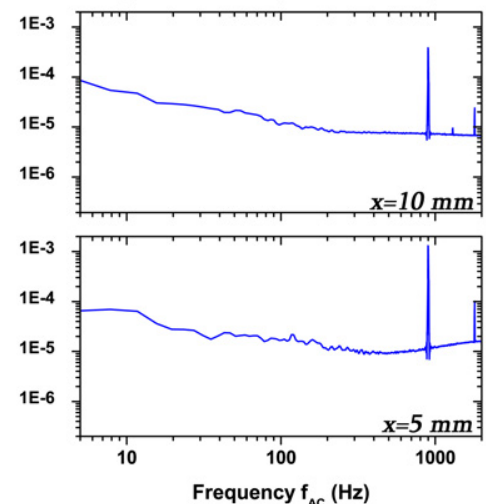

(b)

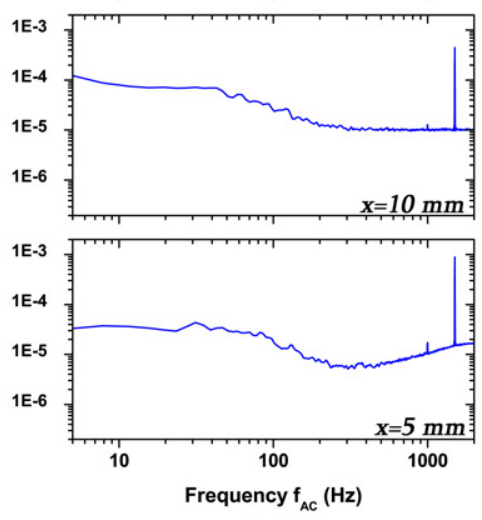

(c)

Figure 6: Power spectra density of the induced electric wind at $\mathrm{y}=1 \mathrm{~mm}$ and three different $\mathrm{x}$ positions $(5,10$ and $15 \mathrm{~mm}$ ) along the dielectric. The applied excitation is a sinusoidal waveform having a fundamental frequency $\mathrm{f}_{\mathrm{AC}}$ of (a) $300 \mathrm{~Hz}$, (b) $900 \mathrm{~Hz}$ and (c) $1500 \mathrm{~Hz}$.

\subsection{Double frequency excitation: Burst modulation}

Sine wave modulated by a burst signal is commonly used as input waveform for DBD dedicated to flow control. The effects of such actuation are widely commented as burst modulation in most cases improves the overall aerodynamic performances [11-12]. The physical reasons of the performance enhancement are presumably related to an action on the natural instability waves of the controlled flows. However, the detailed study of the electric wind resulting from such input signal has rarely been addressed. The analysis of the electric wind formation may be helpful to elucidate the control processes involved when burst modulation is used.

The burst modulation consists of an AC sine signal alternatively switched on and off: the discharge is sustained by the carrier signal while the modulation frequency, $\mathrm{f}_{\mathrm{BM}}$, manages the starting (switching on) and switching off of the discharge. Here, a sine waveform at $\mathrm{V}=18 \mathrm{kV}_{\text {amp }}$ and $\mathrm{f}_{\mathrm{AC}}=1500$ $\mathrm{Hz}$ initiates and sustains the plasma discharge. A train of pulse with a duty-cycle of $50 \%$ modulates the AC sine signal in triggered mode.

The electrical measurements are performed for modulation frequencies $\left(f_{\mathrm{BM}}\right)$ of 50,150 and $300 \mathrm{~Hz}$. The power density spectra of the applied voltage at the air-exposed electrode are plotted in figure 7. It was expected that such modulation results in a pair of sidebands at $f_{A C}$ and $f_{B M}$. The frequency $f_{B M}$ related to the fundamental of the pulse train is evidenced in figure 7 but the signal is enriched by strong harmonics every $\mathrm{nf}_{\mathrm{BM}}$. The frequency $\mathrm{f}_{\mathrm{AC}}$ corresponds to the bump at $1500 \mathrm{~Hz}$. To summarize, input voltage resulting from burst modulation presents a rich frequential content with fundamentals at $\mathrm{f}_{\mathrm{AC}}$ and $\mathrm{f}_{\mathrm{BM}}$ superimposed by numerous harmonics at $\mathrm{nf}_{\mathrm{BM}}$. 

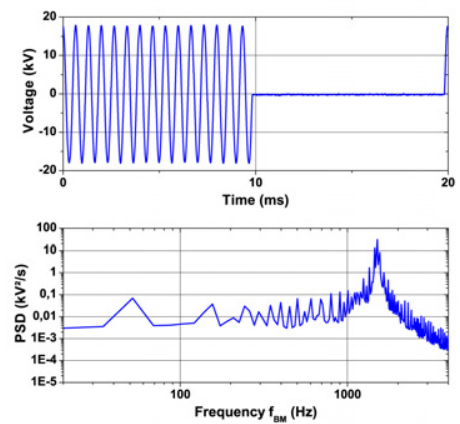

(a)
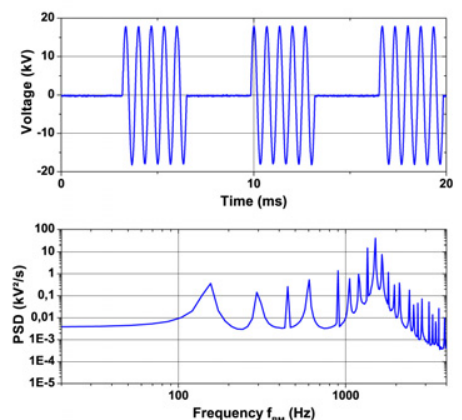

(b)
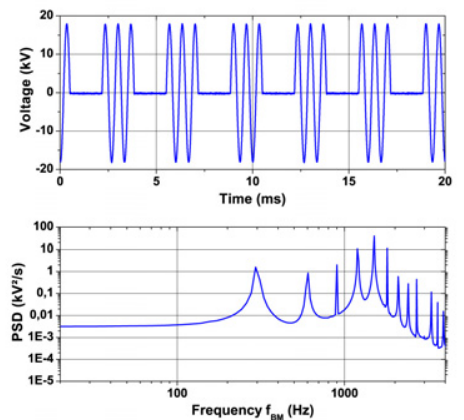

(c)

Figure 7: Measured signals for burst modulation (top figures) and corresponding spectra densities at (a) $\mathrm{f}_{\mathrm{BM}}=50$ $\mathrm{Hz}$, (b) $\mathrm{f}_{\mathrm{BM}}=150 \mathrm{~Hz}$ and (c) $\mathrm{f}_{\mathrm{BM}}=300 \mathrm{~Hz}$.

The time-dependent evolution of the resulting electric wind is shown in figure 8. Results indicate that the momentum transfer is strongly non-stationary. As previously observed in [5], when the discharge is on, the velocity production is related to the negative-going-cycle of the voltage. The positive-going-cycle produces a fluid deceleration resulting in an oscillatory flow at $f_{A C}$. When the plasma is switched off, this period corresponds to the relaxation of the induced airflow. Figure 8 highlights the transient formation process of the electric wind. The airflow production is not instantaneous and several $\mathrm{AC}$ cycles are needed to attain the asymptotic permanent velocity value. Consequently, when modulated at low $\mathrm{f}_{\mathrm{BM}}$, the on period includes enough voltage cycles at $\mathrm{f}_{\mathrm{AC}}$ to reach the maximal flow at the investigated location (here local $u_{\max }$ of about $1.6 \mathrm{~m} / \mathrm{s}$ ). At higher $\mathrm{f}_{\mathrm{BM}}$, the on period is reduced (then the attained velocity is self-limited) but the off period is also shortened. This is of primary importance as the off period duration drives the velocity at its end that is equal to the velocity at the beginning of the next on period. This velocity will be called "initial" velocity. If this time is too short (i.e. too high frequency), the fluid is not fully relaxed when the next on period starts. This results in a positive initial electric wind velocity that reduces the amplitude of velocity fluctuations. Regardless of this initial velocity, the electric wind increases by an AC cumulative effect.

One can also notice that the velocity slope differs for the on and off periods. When the flow naturally relaxes (off period), no body force is applied to the surrounding airflow. During the on period, the flow oscillations suggest that two different body forces are produced over an AC cycle. The negative-going-cycle produces a fluid acceleration resulting in a velocity increase whereas a deceleration is observed during the positive-going-cycle. However, the slope of the decelerating period differs from the slope due to the relaxation, suggesting that an opposite body force is responsible for the flow deceleration. This point has to be investigated in detail in future investigation.

Concerning the time-averaged electric wind, the contribution of the on and off periods is equal. For instance, at $\mathrm{f}_{\mathrm{BM}}=50 \mathrm{~Hz}$, the instantaneous electric wind can reach the saturated velocity whereas the end of the off period corresponds to a minimized airflow. In a time-averaged sense, this results in a low time-averaged velocity and high fluctuating velocity. For unsteady flow control, this aspect 
becomes very crucial because the instabilities are sensitive to the amplitude of fluctuation rather than the attained mean velocity.

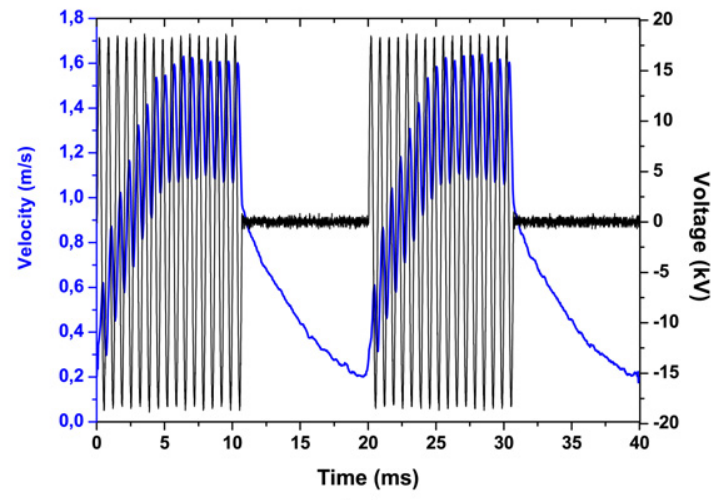

(a)

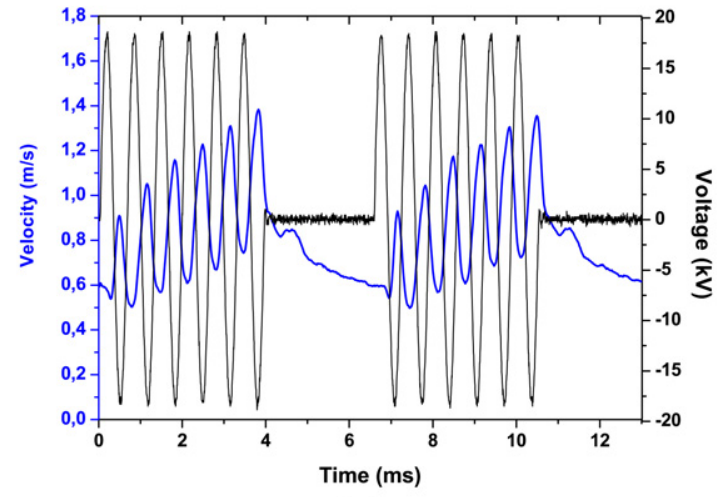

(b)

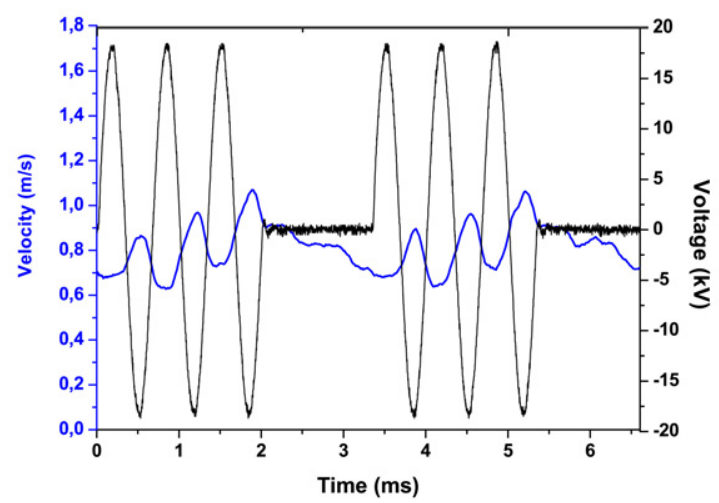

(c)

Figure 8: Time-resolved electric wind (phase reconstruction) when the DBD is operated with burst modulation at $\mathrm{f}_{\mathrm{BM}}$ equal to (a) $50 \mathrm{~Hz}$, (b) $150 \mathrm{~Hz}$ and (c) $300 \mathrm{~Hz}$ (at $\mathrm{x}=3 \mathrm{~mm}$ and $\mathrm{y}=1 \mathrm{~mm}$, duty-cycle of $50 \%$ ).

In the case of burst modulation, the last results shown here relate to the PSD at $\mathrm{y}=1 \mathrm{~mm}$ and $\mathrm{x}=1,3$ and $5 \mathrm{~mm}$ (figure 9). The location of these measurements is motivated by characterization in the plasma vicinity. Indeed, to be effective the plasma discharge has to be at the separation point where instabilities flow and produced fluctuations interact. These spectra present two high energy peaks at $\mathrm{f}_{\mathrm{AC}}$ and $\mathrm{f}_{\mathrm{BM}}$. As compared with the frequency signature of the voltage, the harmonics at $\mathrm{nf}_{\mathrm{BM}}$ are significantly reduced, due to the response of the fluid (see figure 8a). However, the energy contained in these harmonics is increased along the plasma extension. In particular, the frequency signature of the modulating signal can be observed very close to the air-exposed electrode when energies of the carried signal frequencies are more affected by the measurement location along the plasma extension. Non-linear interactions between the frequencies are not observed in the investigated region, i.e. the frequential content is similar to the input electrical signal up to $\mathrm{x}=5 \mathrm{~mm}$. As observed from figure 8 , the energy imparted in the surrounding region is maximized at low frequency when $\mathrm{f}_{\mathrm{BM}}$ is more than one order of magnitude lower than $\mathrm{f}_{\mathrm{AC}}$. 

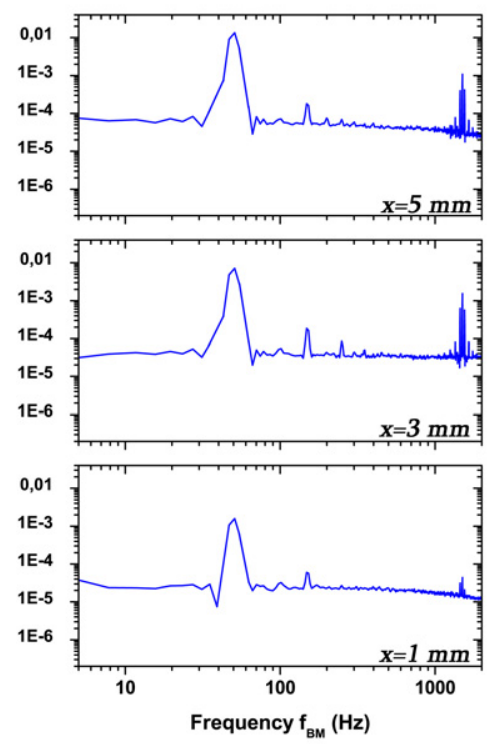

(a)
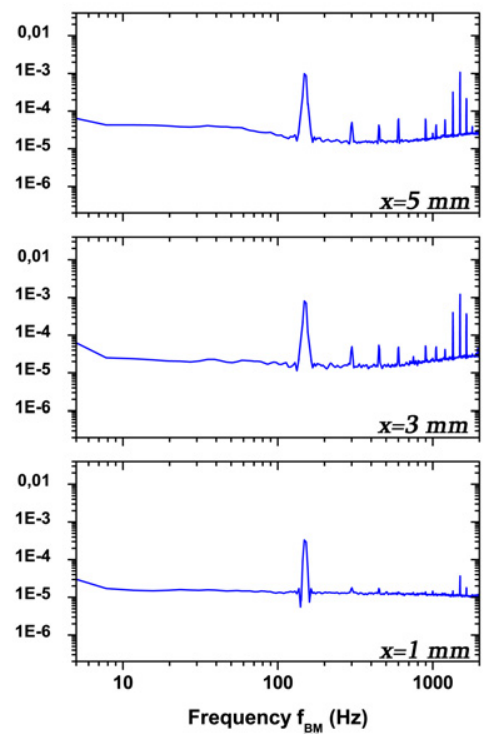

(b)
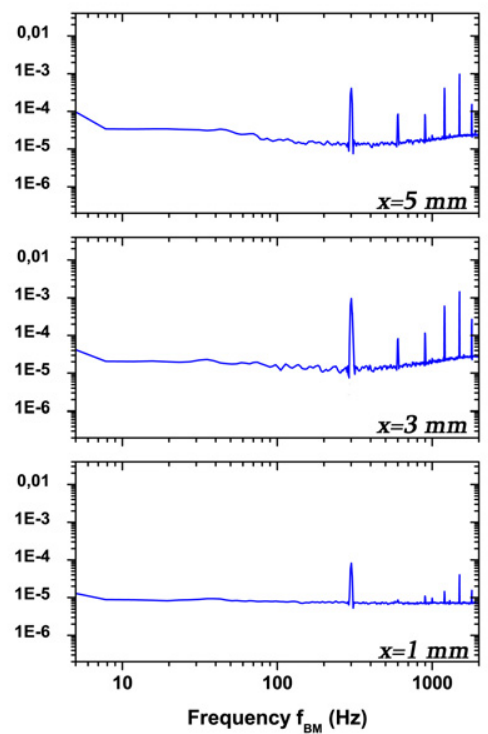

(c)

Figure 9: Power spectra density of the induced electric wind in the plasma region ( $\mathrm{y}=1 \mathrm{~mm}$ and $\mathrm{x}=1,2$ and 3 $\mathrm{mm}$ ) along the plasma extension. The applied excitation is a burst modulation at $\mathrm{f}_{\mathrm{BM}}$ (a) $50 \mathrm{~Hz}$, (b) $150 \mathrm{~Hz}$ and (c) $300 \mathrm{~Hz}$.

\subsection{Double frequency excitation: Superposition modulation}

Superposition modulation is not usual in the literature. In our knowledge, this study is the first proposing a detailed description of the flow produced by such input excitation for non-thermal plasmas. Actuation based on superposition modulation can be very interesting as such signal theoretically results in a pair of sidebands at $\mathrm{f}_{\mathrm{AC}}$ and $\mathrm{f}_{\mathrm{SM}}$. As mentioned in [14, 29], simultaneous actuation at two frequencies separated by an order of magnitude may contribute to enhance the overall control effects by non-linear interactions. Superposition modulation may be an alternative to usual burst modulation.

The superposition modulation consists of summing two sine signals, one having a frequency $f_{A C}$ while the second oscillates at $f_{S M}$. The high frequency signal (at $f_{A C}$ ) is carried by the lower frequency signal at $f_{S M}$. The resulting waveforms for three different values of $f_{S M}$ are plotted in figure $10\left(f_{A C}\right.$ is kept constant at $1500 \mathrm{~Hz}$ ). In the frequential domain, the voltage applied to the air-exposed electrode is composed of two fundamental frequencies (the frequencies of each of the two added signals, i.e. $\mathrm{f}_{\mathrm{AC}}$ and $\mathrm{f}_{\mathrm{SM}}$ ). The superposition modulation conduces to two discrete peaks in the spectral domain (the broad peaks are related to the size of the FFT window) as observed for burst modulation. However, superposition limits the number of harmonics in the applied voltage. 

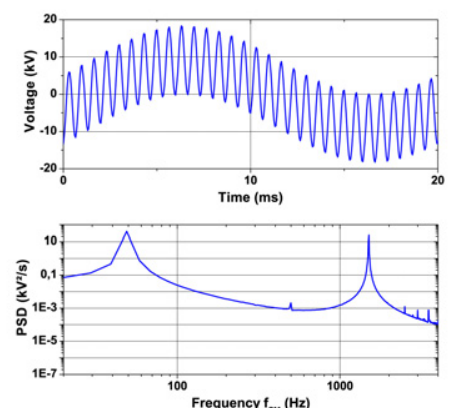

(a)
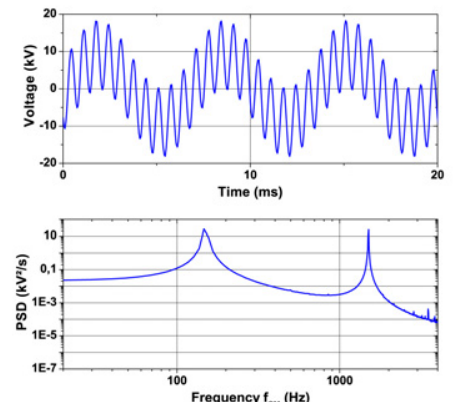

(b)
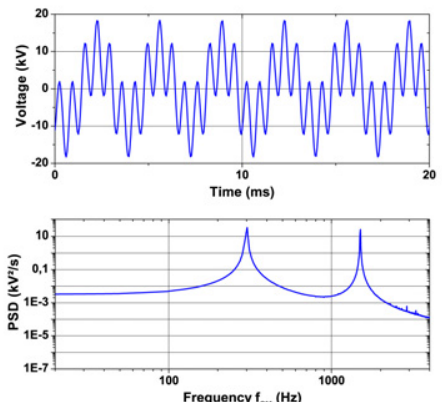

(c)

Figure 10: Superposition signals (top figures) and corresponding spectra densities at (a) $\mathrm{f}_{\mathrm{SM}}=50 \mathrm{~Hz}$, (b) $\mathrm{f}_{\mathrm{SM}}=150 \mathrm{~Hz}$ and $(\mathrm{c}) \mathrm{f}_{\mathrm{SM}}=300 \mathrm{~Hz}\left(\mathrm{f}_{\mathrm{AC}}=1500 \mathrm{~Hz}\right.$ for all cases $)$.

The time-resolved electric wind close to the tip of the air-exposed electrode is shown in figure 11. Again, a positive momentum transfer occurs for the negative-going-cycle whereas the positive cycle leads to an abrupt reduction of the velocity. This asymmetric behavior results from the two discharge modes occurring at each change in the voltage gradient as observed for typical AC sine [5, 30-31]. The present results indicate that these two modes also exist for an unusual input waveform. Furthermore, results suggest that higher momentum transfer is produced for AC regions having a negative mean.

The two frequencies are visible in the time evolution of the electric wind. The attained velocity strongly depends on the frequency $\mathrm{f}_{\mathrm{SM}}$. Furthermore, the produced electric wind presents a significantly lower induced velocity and fluctuating amplitude than the ones generate by burst modulation and usual unmodulated sine wave. When $\mathrm{f}_{\mathrm{SM}}$ is increased, the resulting electric wind velocity is amplified but it is not guaranteed that the produced velocity amplitude will be large enough to manipulate airflow even at low Reynolds number. Moreover, effective and universal plasma actuators designed for instability wave control requires a sufficient velocity and fluctuations amplitude, regardless of chosen $\mathrm{f}_{\mathrm{SM}}$. This point could be overcome by a suitable optimization. In particular, change in amplitude ratio between carrier and carried signals may enhance the produced electric wind. 


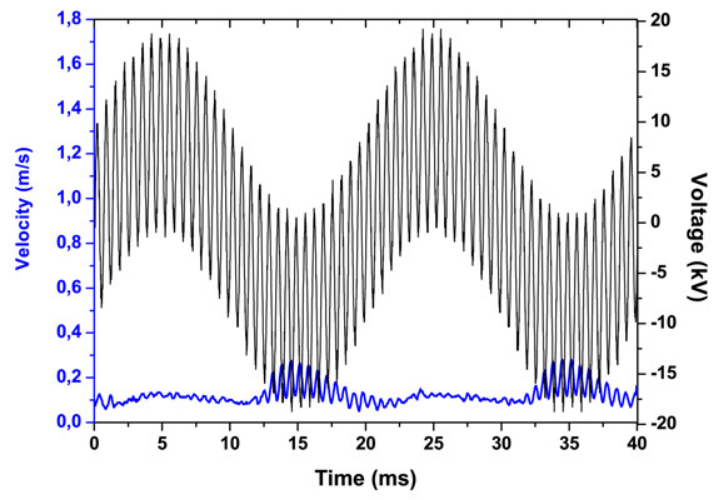

(a)

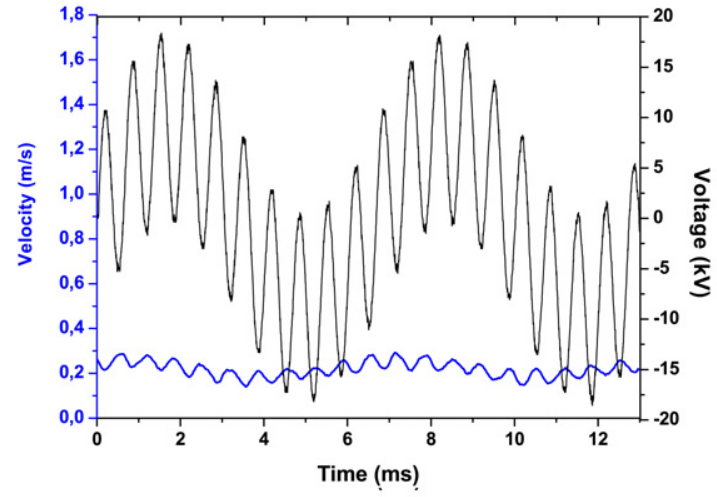

(b)

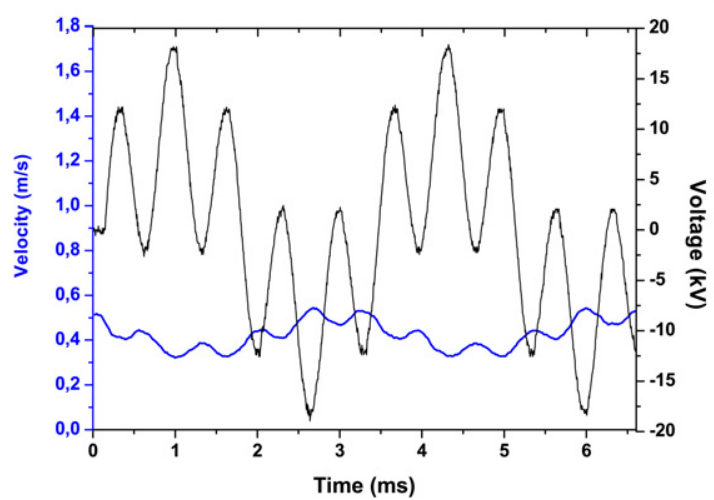

(c)

Figure 11: Time-resolved electric wind (phase reconstruction) when the DBD is operated with superposition modulation at $\mathrm{f}_{\mathrm{SM}}$ equal to (a) $50 \mathrm{~Hz}$, (b) $150 \mathrm{~Hz}$ and (c) $300 \mathrm{~Hz}$ (at $\mathrm{x}=3 \mathrm{~mm}$ and $\mathrm{y}=1 \mathrm{~mm}$ ).

The PSD evolution along the plasma extension is shown in figure 12. At each position, the spectra content two fundamental frequencies at $\mathrm{f}_{\mathrm{AC}}$ and $\mathrm{f}_{\mathrm{SM}}$ as it was observed from the voltage (figure 10). On the one hand, the frequency analysis shows a similar signature than the one reported for burst modulation. On the other hand, two major differences can be observed a) the frequency content is impoverished as no significant harmonics occur b) the involved energies largely differ. The mean energy, as well as the energy related to the fundamental frequencies, are lower in the case of superposition modulation as suggested by the time-history of produced velocity. The evolution of the energies along the $x$ direction indicates that the fluctuating level is enhanced with the distance from the tip of the air-exposed electrode. The mean fluctuating level and the energy of the peaks related to the two fundamental frequencies are progressively amplified along the plasma discharge. It can be supposed that the flow incurs an energy gain due to cumulative effect when the plasma extends further downstream.

The superposition modulation is an alternative to burst modulation for dual-frequency forcing. At the same amplitude, the absence of harmonics in the induced flow could lead to enhanced nonlinear interaction by selecting specific frequencies. The current disadvantage on the amplitude of the generated fluctuations should be resolved in the future by optimizing the applied waveform. 

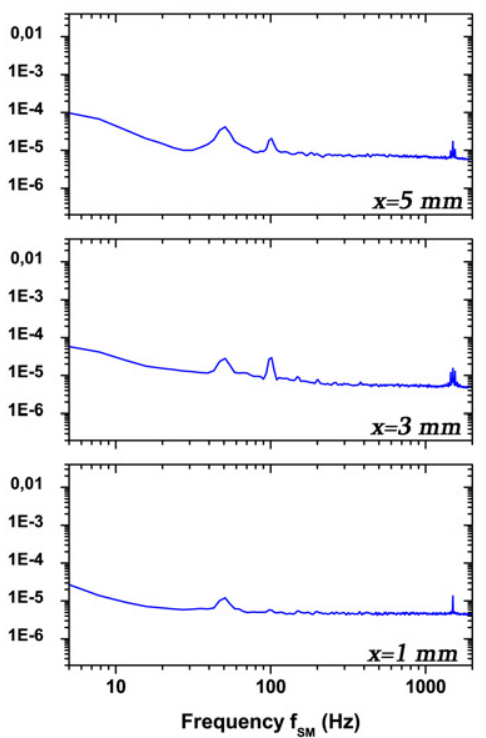

(a)
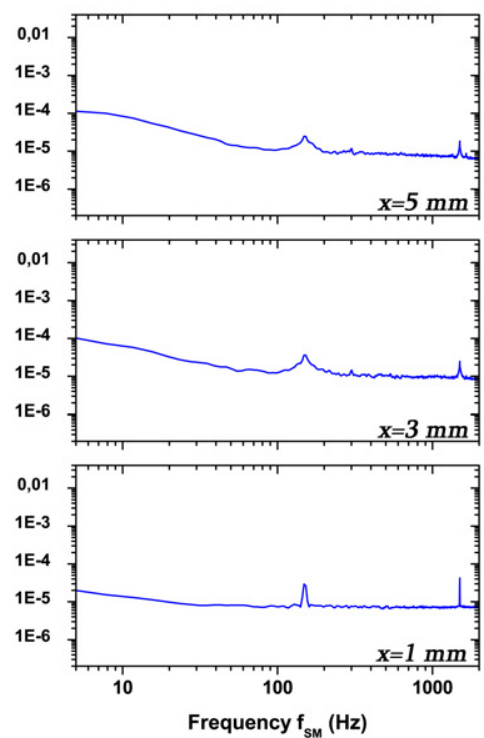

(b)
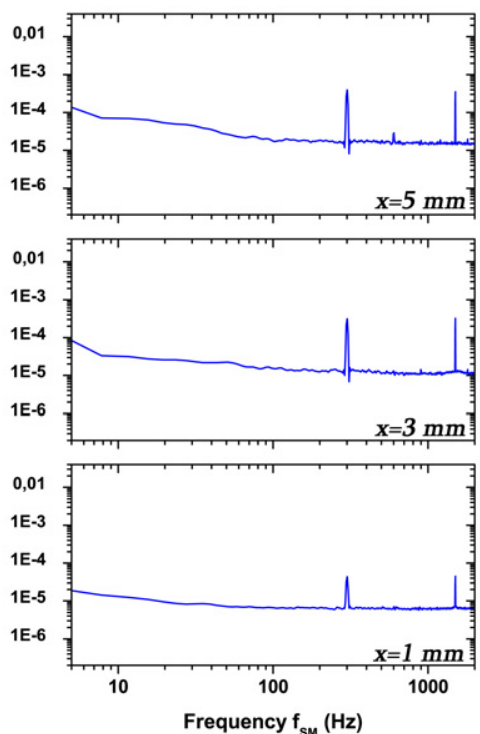

(c)

Figure 12: Power spectra density of the induced electric wind in the plasma region $(\mathrm{y}=1 \mathrm{~mm}$ and $\mathrm{x}=1,2$ and 3 $\mathrm{mm}$ ) along the plasma extension. The applied excitation is a superposition modulation at $\mathrm{f}_{\mathrm{SM}}$ (a) $50 \mathrm{~Hz}$, (b) 150 $\mathrm{Hz}$ and (c) $300 \mathrm{~Hz}$.

\subsection{Double frequency excitation: Ring modulation}

Ring or amplitude modulations are rarely used as input waveform in flow control studies. In 2008, Little et al. performed flow separation control experiments in which a single DBD was operated by amplitude modulation with index modulation of unity [30]. In their attempt to maximize the lift performance, they demonstrate the potential of amplitude modulation. However, no comparison for burst and amplitude modulation was proposed. In 2006, Tian et al. [29] used amplitude and burst modulation to minimize the lift-to-drag ratio for post-stall flow controlled by zero-net-mass-flux actuator (synthetic fluidic system). The best performances were observed in the case of amplitude modulation. This contradicts the study of Naim et al. [32] where a difference in effectiveness was observed between burst and amplitude modulation in favour of the former one. The authors suggest that this difference may result from a different spectral content in the two forcing modes. Concerning flow control by plasma, the improvement of the performances by using amplitude modulation methods is not established. Then, it is necessary to study the flow resulting from such a modulation before considering its applications.

Excitations of the DBD by a carrier frequency of $1.5 \mathrm{kHz}$ with modulations at $\mathrm{f}_{\mathrm{RM}}$ equal to 50 , 150 and $300 \mathrm{~Hz}$ are investigated. The ring modulation is performed by simply multiplying two sine signals. This modulation results in the waveforms introduced in figure 13 and approaches an amplitude modulation performed with a modulation index equal to one (i.e., the carrier signal varies by $100 \%$ around its unmodulated level). At low $\mathrm{f}_{\mathrm{RM}}$, the signal is obviously composed of several high amplitude $\mathrm{AC}$ cycles whereas higher $\mathrm{f}_{\mathrm{RM}}$ reduces the number of $\mathrm{AC}$ cycles oscillating in amplitude at 
$\pm 18 \mathrm{kV}_{\text {amp. }}$. According to the construction of the input signal, two frequency peaks at $\mathrm{f}_{\mathrm{AC}}-\mathrm{f}_{\mathrm{RM}}$ and $f_{A C}+f_{R M}$ were expected and are verified in the PSDs. However, the voltage signal at the air-exposed electrode presents additional perturbations at $f_{R M}$ harmonics. This is due to a non integer number of $\mathrm{AC}$ cycles (duration equal to $\mathrm{T}_{\mathrm{AC}}=1 / \mathrm{f}_{\mathrm{AC}}$ ) in an half-period of the carrier signal (duration equal to $\mathrm{T}_{\mathrm{RM}} / 2$ with $\left.\mathrm{T}_{\mathrm{RM}}=1 / \mathrm{f}_{\mathrm{RM}}\right)$.
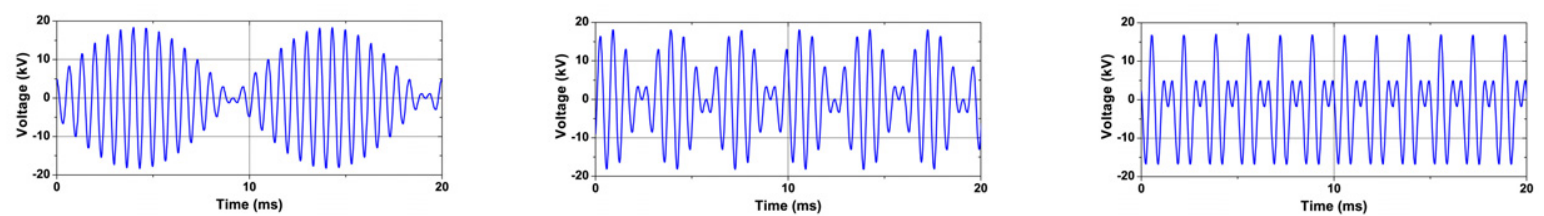

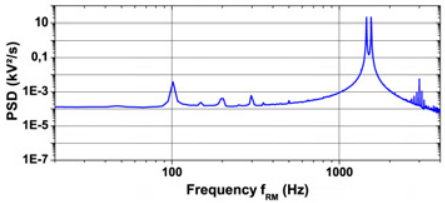

(a)

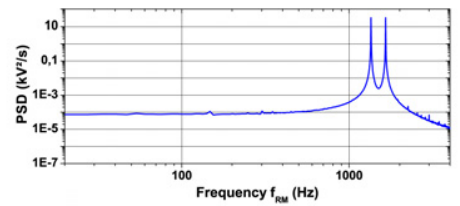

(b)

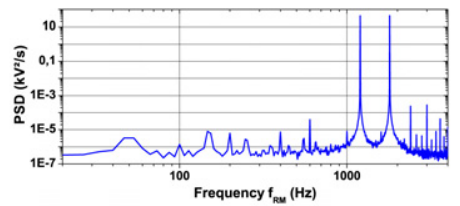

(c)

Figure 13: Ring modulation signals (top figures) and corresponding spectra densities at (a) $f_{R M}=50 \mathrm{~Hz}$, (b) $f_{R M}=$ $150 \mathrm{~Hz}$ and (c) $\mathrm{f}_{\mathrm{RM}}=300 \mathrm{~Hz}$.

The reconstructed time-history of the electric wind is plotted in figure 14. At low $f_{R M}$, some parts of the input electrical signal are ineffective to bring momentum to the surrounding air. When the change in voltage is sufficiently large to ignite the discharge, the surrounding airflow incurs a flow acceleration driven by the signal at $\mathrm{f}_{\mathrm{AC}}$. The maximal velocity is formed by a cumulative effect of the previous fluid accelerations. The lowest $\mathrm{f}_{\mathrm{RM}}$ conduces to the higher instantaneous velocity but it is also related to the largest velocity fluctuations as it was observed with burst modulation. When $f_{R M}$ is increased, the fluctuation amplitudes and the maximal velocity are reduced. Despite similar fundamental frequencies, the temporal evolution and the mean values of the electric wind for ring modulation significantly differs from the one reported for superposition modulation. As a result, it appears that the ring modulation, even in its non-optimized form (as presented here), may result in larger control authority due to higher velocity amplitude. 


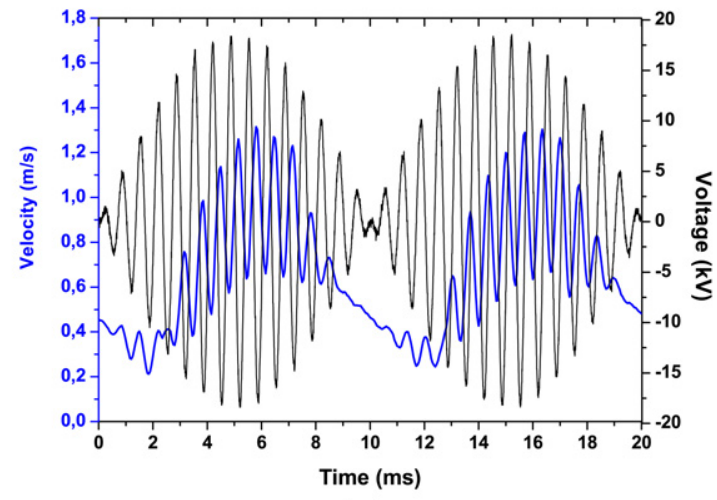

(a)

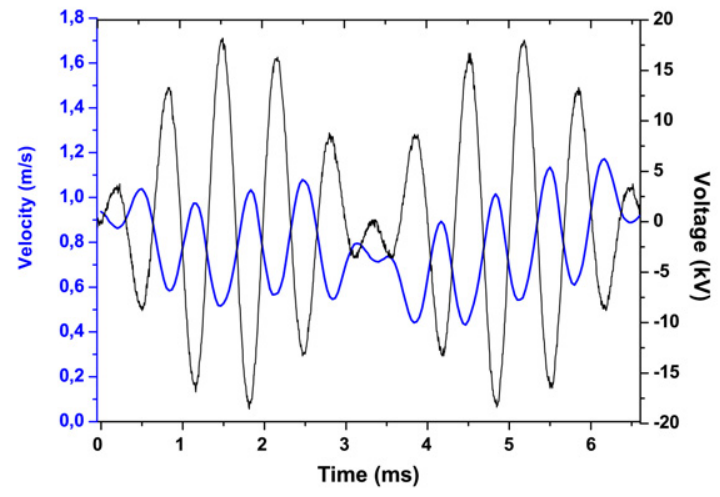

(b)

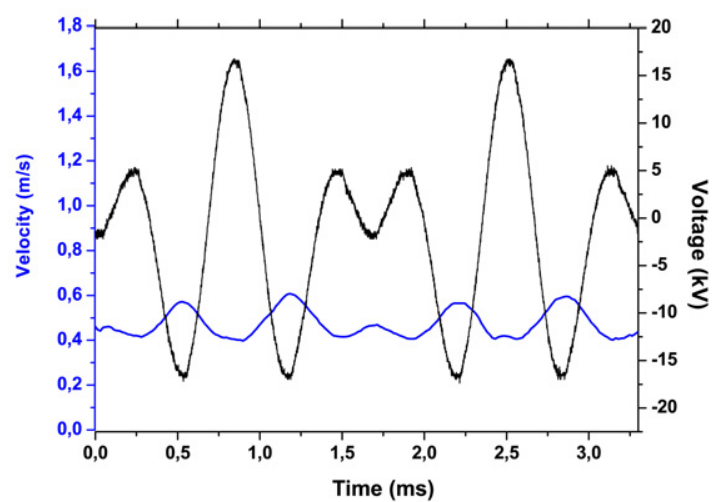

(c)

Figure 14: Time-resolved electric wind (phase reconstruction) when the DBD is operated by ring modulation at $\mathrm{f}_{\mathrm{RM}}$ equal to (a) $50 \mathrm{~Hz}$, (b) $150 \mathrm{~Hz}$ and (c) $300 \mathrm{~Hz}$ (at $\mathrm{x}=3 \mathrm{~mm}$ and $\mathrm{y}=1 \mathrm{~mm}$ ).

The fluid response to the plasma discharge in the frequency domain is presented in figure 15. The two peaks at $\mathrm{f}_{\mathrm{AC}}-\mathrm{f}_{\mathrm{RM}}$ and $\mathrm{f}_{\mathrm{AC}}+\mathrm{f}_{\mathrm{RM}}$ are transmitted to the surrounding airflow initially at quiescent condition. However, these peaks are not necessarily the most energetic in comparison with peaks at $2 \mathrm{f}_{\mathrm{RM}}$ (at $100 \mathrm{~Hz}, 300 \mathrm{~Hz}$ and $600 \mathrm{~Hz}$ for $\mathrm{f}_{\mathrm{RM}}=50,150$ and 300, respectively). As observed for zero-netmass-flux actuator $[29,33]$, the input signal is demodulated by the plasma actuator. For instance, two oscillating velocity patterns can be produced over a ring modulation period due to fluid relaxation when the change in voltage fails to promote velocity production (Figure 14a, between $\mathrm{t}=8$ and $12 \mathrm{~ms}$ ). As a result, the fluid response to the actuation has a proper frequency at $2 \mathrm{f}_{\mathrm{RM}}$. The two sideband peaks (at $\mathrm{f}_{\mathrm{AC}}-\mathrm{f}_{\mathrm{RM}}$ and $\mathrm{f}_{\mathrm{AC}}+\mathrm{f}_{\mathrm{RM}}$ ) are visible in the near field region of the air-exposed electrode and they are amplified further downstream, regardless of $f_{R M}$. The energetic evolution of broadband peak at $2 f_{R M}$ differs. The frequency $f_{R M}$ is first energized between 1 and $3 \mathrm{~mm}$, but further downstream the peak energy is reduced at the same level than the one at $\mathrm{x}=1 \mathrm{~mm}$. Beyond the end of the plasma extension, fluctuations vanish, only both fundamental peaks $f_{A C}-f_{R M}$ and $f_{A C}+f_{R M}$ remain. This is especially verified at high $\mathrm{f}_{\mathrm{RM}}$ (larger than $150 \mathrm{~Hz}$ ). At low modulating frequency, the life-time of the $2 \mathrm{f}_{\mathrm{RM}}$ harmonics is longer, as observed in figure 15a. The amplitude of fluctuation is larger and then more difficult to be dissipated further downstream. 

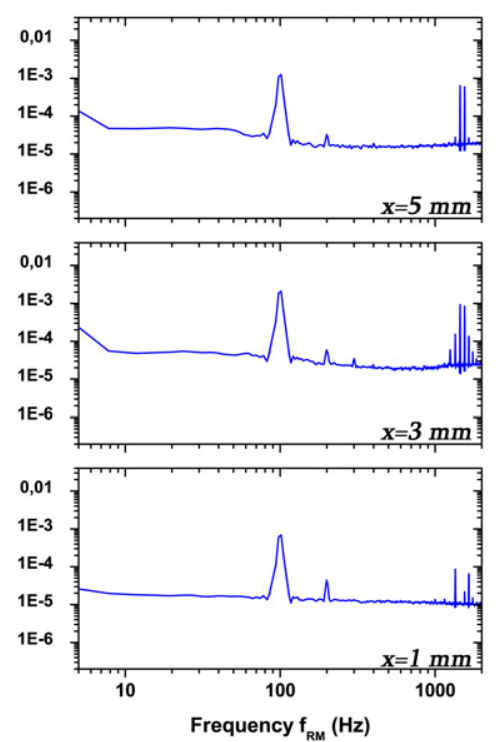

(a)
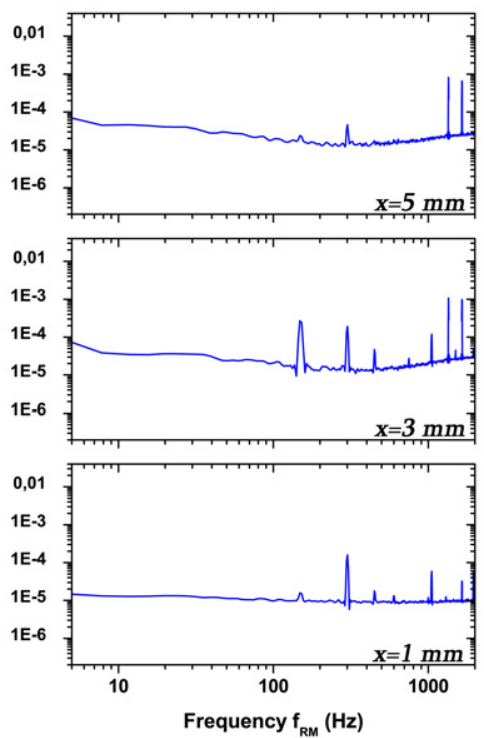

(b)
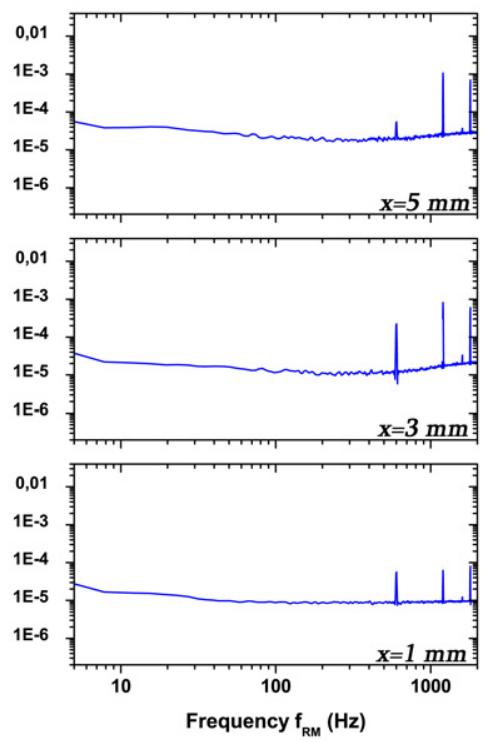

(c)

Figure 15: Power spectra density of the induced electric wind in the plasma region ( $\mathrm{y}=1 \mathrm{~mm}$ and $\mathrm{x}=1,2$ and 3 $\mathrm{mm}$ ) along the plasma extension. The applied excitation is a ring modulation at $\mathrm{f}_{\mathrm{RM}}$ (a) $50 \mathrm{~Hz}$, (b) $150 \mathrm{~Hz}$ and (c) $300 \mathrm{~Hz}$.

Initially, it was expected that superposition or burst modulation are preferred if the objective is to act on two frequencies of the free flow (to act on the shear layer and wake instabilities as suggested by $[14,29])$. The present results highlight the non linear response of the actuator when it operates in ring modulation. This response results in excitation at $2 f_{R M}, f_{A C}-f_{R M}$ and $f_{A C}+f_{R M}$, excitation that can meet the needs for the forcing of non linear interactions. In its present form, the ring modulation does not produce large velocity at high $\mathrm{f}_{\mathrm{RM}}$ but, as indicated for the superposition modulation, larger velocities can be expected by a suitable optimization or addition of a DC offset to form a typical amplitude modulation with adjustable index modulation.

\section{Conclusion and perspectives}

The present study deals with the characterization of the electric wind produced by a single DBD supplied by different modulated input waveforms. The plasma is ignited and self-sustained by a sine waveform at $\mathrm{V}=18 \mathrm{kV}_{\mathrm{amp}}$ and frequency $\mathrm{f}_{\mathrm{AC}}$ equal to $1500 \mathrm{~Hz}$. This case, usually qualified as a 'quasisteady' actuation is briefly described. The main part of the present paper focuses on three different types of modulations: burst modulation, superposition modulation and ring modulation. A description of the resulting time-resolved electric wind is proposed as well as the frequency signature of airflow produced along plasma discharge. Plasma actuators are recognized as useful systems due to their large bandwidth. Here, the objective was to highlight the capability of plasma actuator in term of multifrequency excitation. 
The results demonstrate that the plasma systematically produces a local flow, regardless of the modulation of the input voltage. Naturally, the resulting time-averaged velocities as well as the fluctuating amplitudes differ according to the modulation. Simple and double frequency fluctuations can be produced, without or with strong harmonics. This may be helpful to effectively act on the instability phenomena, enhance or cancel the linear and non-linear interactions occurring in turbulent flows.

The results presented here also provide an insight to the temporal formation process of the electric wind and bring new considerations for future flow control experiments. Indeed, the time-resolved evolution of the electric wind formation and the spectra analysis interesting properties are highlighted. For instance, it appears that burst modulation results in two frequential peaks having a high energy superimposed by numerous harmonics. This multi-frequency property may explain the effectiveness of burst modulation in term of aerodynamic performance increase when the frequencies are adjusted to the shedding frequency of the natural coherent flow structures. Electric wind resulting from superposition and ring modulations also presents intrinsic properties having potential benefits for flow control. Superposition modulation can produce two narrowed energy peaks at two frequencies possibly separated by one or several orders of magnitude. This may be useful to simultaneously act on shear layer instability and wake instability usually observed in the case of separated flows. However, the fluctuation amplitude remains quite low. This constitutes a significant drawback for high speed flow control but such signal having only two frequency components can be a fundamental tool to probe at linear and non-linear interactions in studies at low freestream velocities. The ring modulation may have additional interest. The two close energy peaks can be adjusted to frame the frequency range of the flow structures targeted by the control strategy. Moreover, the present results indicate that ring modulation (approaching amplitude modulation at index modulation equal to one) also produce significant fluctuations at twice the modulating frequency. This has to be considered when one plans to act on a specific frequency.

Lot of parameters of the input signal remain to be investigated. Indeed, in the present study the duty-cycle is fixed at $50 \%$ and different results are expected for other duty-cycle values. Moreover, the attained amplitude in term of mean and fluctuating velocity may be enhanced by an optimization study as currently some part of the input signal fails to create momentum transfer. It is expected that optimization of the modulation waveform may improve this transfer. In future experiments, the electric wind resulting from frequency modulation, phase-shift modulation, frequency-shift modulation and tonal input signals will be characterized. Finally, non-linear forcing strategy will be developed further in the upcoming months to control planar free shear layer. 


\section{References}

[1] Wang, Y H , Zhang Y T and Wang D Z 2007 Period multiplication and chaotic phenomena in atmospheric dielectric barrier glow discharge Appl. Phys. Let. 90071501

[2] Singh K P, Roy S and Gaitonde D V 2006 Modeling of dielectric barrier discharge plasma actuator with atmospheric air chemistry AIAA paper 2006-3381

[3] Roth J R, Sherman D M and Wilkinson S P 2000 Electrohydrodynamic flow control with a glow-discharge surface plasma AIAA J. 38 1166-1178.

[4] Pons J, Moreau E and Touchard G 2005 Asymmetric surface dielectric barrier discharge in air at atmospheric pressure: electrical properties and induced airflow characteristics J. Phys. D: Appl. Phys. 38 3635-3642.

[5] Forte M, Jolibois J, Pons J, Moreau E, Touchard G and Cazalens M 2007 Optimization of a dielectric barrier discharge actuator by stationary and non-stationary measurements of the induced flow velocity: application to airflow control Exp. Fluids 43 917-928

[6] Borghi C A, Carraro M R, Cristofolini A and Neretti G 2008 Electrohydrodynamic interaction induced by a dielectric barrier discharge J. Appl. Phys. 103063304

[7] Singh K P and Roy S 2005 Simulation of an asymmetric single dielectric barrier plasma actuator J. Appl. Phys. 98083303

[8] Boeuf J P, Lagmich Y and Pitchford L C 2009 Contribution of positive and negative ions to the electrohydrodynamic force in a dielectric barrier discharges plasma actuator operating in air J. Appl. Phys. 106 023115-9

[9] Roth J R and Dai X 2006 Optimization of the aerodynamic plasma actuator as an EHD electrical device AIAA paper 2006-1203

[10] Jolibois J and Moreau E 2009 Enhancement of the electromechanical performances of a single dielectric barrier discharge actuator IEEE trans. Diel. Elect. Insulat. 16 758-767

[11] Moreau E 2007 Airflow control by non-thermal plasma actuators J. Phys. D: Appl. Phys. 40 605-636

[12] Corke T C and Post M L 2005 Overview of plasma flow control: concepts, optimization and applications AIAA paper 2005-563

[13] Gad-el-Hak M 2000 Flow Control: Passive, Active, and Reactive Flow Management Cambridge University Press, London, United Kingdom

[14] Mittal R, Kotapati R and Cattafesta L 2005 Numerical study of resonant interactions and flow control in a canonical separated flow AIAA paper 2005-1261

[15] Wiltse J M and Glezer A 1998 Direct excitation of small scale motions in free shear flows Phys. Fluids 8 2026-2036

[16] Stanek M, Sinha N, Seiner J, Pearce B and Jones M 2002 Applying Very High Frequency Excitation to the Problem of Tactical Directed Energy Beam Propagation AIAA paper 2002-2272

[17] Bonnet J P 2009 Introduction and fluid mechanic for flow control VKI lecture series 'Flow control: fundamentals, advances and applications'

[18] Moreau E and Benard N 2009 Plasmas for flow control VKI lecture series 'Flow control: fundamentals, advances and applications

[19] Grundmann S and Tropea C 2009 Experimental damping of boundary-layer oscillations using DBD plasma actuators Int. J. Heat Fluid Flow 30 394-402 
[20] Benard N, Balcon N and Moreau E 2009 Jet flow control by dielectric barrier discharge - Excitation by axisymmetric and flapping modes AIAA paper 2009-0776

[21] Benard N, Braud P, Jolibois J and Moreau E 2008 Airflow reattachment along a NACA 0015 airfoil by surface dielectric barrier discharge actuator - Time resolved particle image velocimetry investigation AIAA paper 2008-4202

[22] Jukes T and Choi K S 2009 Long Lasting Modifications to Vortex Shedding Using a Short Plasma Excitation Phys. Rev. Lett. 102254501

[23] Boucinha V, Magnier P, Weber R, Leroy-Chesneau A, Dong B, Hong D and Joussot R 2008 Characterization of the Ionic Wind Induced by a Sine DBD Actuator Used for Laminar- to- Turbulent Transition Delay AIAA paper 2008-4210.

[24] Benard N and Moreau E 2009 Electric wind produced by a surface plasma discharge energized by a burst modulated high voltage Proc. of the $29^{\text {th }}$ ICPIG, 12-17 july, 2009

[25] Chang J S, Brocilo D, Urashima K, Mizeraczyk J, Dekowski J et al. 2004 Optimization of seed-particle size and density used in the particle image velocimetry under corona discharges and non-thermal plasmas Proc. 7th Int. Conf. on Optical Particle Characterizations, pp.435-440, Kyoto, Japan, August 2004

[26] Van Maanen H R E, Nobach H and Benedict L H 1999 Improved estimator for the slotted autocorrelation function of randomly sampled LDA data', Meas. Sci. and Techn. 10 L4-L7

[27] Likhanskii AV, Shneider M N, Macheret S O, and Miles R B Modeling of dielectric barrier discharge plasma actuators driven by repetitive nanosecond pulses, Phys. Plasmas 14 073501.1-073501.8

[28] Dong B, Bauchire, J M, Pouvesle, J M, Magnier P, and Hong D Experimental study of a DBD surface discharge for the active control of subsonic airflow, J. Phys. D.: Appl. Phys. 41

[29] Tian Y, Cattafesta L N and Mittal R Adaptive Control of Separated Flow AIAA Paper 2006-1401

[30] Porter C O, Baughn J W, McLaughlin T E, Enloe C L and Font G I 2007 Plasma actuator force measurements AIAA J. 45 1562-1570

[31] Orlov D M, Font G I and Edelstein D 2008 Characterization of discharge modes of plasma actuators AIAA J. 46 3142-3148

[32] Naim, A, Greenblatt D, Seifert A, Wygnanski I 2007 Active control of a circular flow at transitional Reynolds numbers Flow Turb. Combust. 78 387-407

[33] Wiltse J M and Glezer A 1993 Manipulation of free shear flows using piezoelectric actuators J. Fluids Mech. 249 261-285 